\title{
Spatial and Temporal Variations of Drought in Inner Mongolia, China
}

\author{
Qiang An ${ }^{1}\left(\mathbb{D}\right.$, Huaxiang He ${ }^{1, *}$, Qianwen $\mathrm{Nie}^{2}$, Yingjie Cui ${ }^{1}{ }^{\circledR}$, Juanjuan Gao ${ }^{1}{ }^{\mathbb{D}}$, \\ Chuanjiang Wei ${ }^{1}$, Xinmin $\mathrm{Xie}^{1}$ and Jinjun You ${ }^{1}$ \\ 1 State Key Laboratory of Simulation and Regulation of Water Cycle in River Basin, \\ China Institute of Water Resources and Hydropower Research, Beijing 100038, China; \\ anqiang666@126.com (Q.A.); cuiyj@iwhr.com (Y.C.); xiaoxiao.mychoice@163.com (J.G.); \\ wchj@iwhr.com (C.W.); xiexm@iwhr.com (X.X.); youjj@iwhr.com (J.Y.) \\ 2 School of Renewable Energy, North China Electric Power University, Beijing 102206, China; \\ nieqianwen97@163.com \\ * Correspondence: hehx@iwhr.com; Tel.: +86-10-687-857-08
}

Received: 20 May 2020; Accepted: 13 June 2020; Published: 16 June 2020

check for updates

\begin{abstract}
Drought has become an important natural disaster, affecting the development of Inner Mongolia, as an important animal husbandry region in China. In this study, the characteristics and trends of the Inner Mongolia drought are thoroughly analysed by calculating the standardised precipitation evapotranspiration index (SPEI) at different time scales, based on monthly precipitation and temperature data from 40 national meteorological stations in Inner Mongolia from 1958 to 2019. Subsequently, the area drought intensity (ADI), which is a comprehensive evaluation indicator for evaluating drought intensity within the region, is proposed, taking into account the effects of the persistent drought on drought intensity. The results show that drought has increased during this period, with a remarkable increase in the frequency and the area of drought. The areas with stronger drought intensity are mainly located in the west, north central, and the western area of the east. Since 2000, March to October are identified as drought-prone months and April is characterised as the month with the highest frequency of drought. The inflection points of SPEI and climate conditions both appeared in 1990s and it is speculated that the increase in drought may have been caused by excessive temperature rise. The frequency, coverage area, and continuous duration of drought have increased greatly after climate mutation in this region. According to the changes in the spatial distribution of the ADI and frequency of drought occurrence, the drought-stricken areas shifted from the southeast to the northwest after climate mutations. The findings from this study provide a theoretical basis for the drought management of Inner Mongolia.
\end{abstract}

Keywords: drought characteristics; SPEI; climate change; Inner Mongolia

\section{Introduction}

Drought is a complex and multivariate phenomenon influenced by diverse physical and biological processes [1], whose characteristics vary significantly with geography and climate [2]. As a recurring natural disaster, drought is difficult to identify, (including the start, end, extent, and intensity), predict, and mitigate [3]. Drought has many negative effects on agriculture, animal husbandry, water resources, as well as natural and social ecosystems [4]. The multiple severe and long-lasting droughts in South Asia have posed tremendous impacts on growing economies and furthered the water crisis and food scarcity of the region [3]. El Niño-Southern Oscillation, Asian monsoons and tropical Atlantic sea surface temperatures have played a large role in the recent drying [5], and the additional presence of a positive Indian Ocean dipole event severely exacerbates El Niño's drought-inducing effect over 
large areas of monsoon and temperate Asia, including Southeast Asia, Indonesia, eastern China and much of continental Asia north and west of the Himalayas [6]. Studies have identified the presence of a widespread drought at the global land level, with the most severe drought in Eurasia and Africa [7]. Since the 1970s, global aridity has increased significantly due to recent drying over Africa, eastern Australia, East and South Asia, and southern Europe [5]. Global warming is expected to increase the frequency and intensity of droughts in the twenty-first century [8]. Meanwhile, climate models project increased aridity in the twenty-first century over most of the Americas, southern Europe and the Middle East, and most of Africa, Australia, and Southeast Asia [5]. Under the influence of climate warming, subtropical dry regions are expected to get drier and expand polewards [9]. Indeed, for the past several decades, drought events have increased in both Central Asia [10] and South Asia [3]. The frequency, duration, and scope of droughts in China continue to expand in recent decades [11], especially in northern China, where severe and extreme drought events occur more frequently [12-14].

At present, the drought index is used by most scholars to describe the degree of regional drought. To assess the frequency, duration, severity, and spatial extent of meteorological drought, hundreds of drought indices have been so far developed [15], among which, the Palmer drought severity index (PDSI) [16,17], the standardized precipitation index (SPI) [18,19], and the standardized precipitation evapotranspiration index (SPEI) [4,20-22], which are popularly used around the world. Despite their widespread use, the PDSI and the SPI have their own shortcomings. For instance, the PDSI has a strong subjectivity in defining the drought level [20] and the SPI only considers precipitation factors, without considering the influence of temperature and other factors [23]. The SPEI combines the advantages of the PDSI and the SPI; it not only retains the advantage of the PDSI, i.e., considering evapotranspiration sensitive to temperature, but also shows the multi-scale characteristics of the SPI and the calculation results are more reliable. Therefore, the SPEI is more suitable for evaluating regional drought in the context of global warming and has become an ideal indicator for evaluating drought [24,25]. Currently, SPEI has been widely used in drought monitoring and evaluation around the world, including North America, Asia, Europe, Africa, and Australia [26-33].

Inner Mongolia has a large east-west span, mostly located in arid and semi-arid areas, hence it is more sensitive and vulnerable to climate change [34]. Many scholars have used the PDSI [35], meteorological drought comprehensive index (MCI) [36], precipitation anomaly percentage [37], SPI [38], SPEI [39], and other drought indicators to analyse the drought situation in the entire or part of Inner Mongolia. Since the principle, emphasis, and purpose of the calculation methods of different drought indicators are different, the conclusions of those studies are different. Meanwhile, the length of the time series of the meteorological data will also affect the results for some indicators. For many of these indicators, the results are mainly determined using only precipitation data. Nevertheless, in areas with a large potential evapotranspiration (PET), the degree of drought is more affected by the PET [40]. Therefore, in this study, the SPEI, which considers the effects of evapotranspiration, is selected as the main evaluation index. In the context of climate warming, droughts have continually occurred during recent years and continuous droughts will have a certain cumulative effect and cause greater damage to the economic and social development. Therefore, in order to better reflect the degree of damage, caused by drought, and its spatial distribution, this study considers the impact of continuous drought on the drought intensity on the basis of the SPEI to identify the area drought intensity (ADI). This study aims to (1) analyse the drought situation in Inner Mongolia from 1958 to 2019, using the SPEI, as the main evaluation indicator, combined with the ADI; (2) evaluate the impact of climate warming on drought, through analysing the drought situation in time intervals according to the changes in climate conditions.

\section{Study Area}

The Inner Mongolia region is located in the northern border of China and in the mid-latitude inland of East Asia $\left(97^{\circ} 12^{\prime}-126^{\circ} 04^{\prime} \mathrm{E}, 37^{\circ} 24^{\prime}-53^{\circ} 23^{\prime} \mathrm{N}\right)$, with a narrow and long terrain. Inner Mongolia is rich in natural forest and grass, resources and ecological types, so it is sensitive to global warming. 
This region is the largest animal husbandry province of China, and its economic production is greatly affected by grassland animal husbandry and agriculture. In 2019, the total annual grain output of the region was 36.55 billion $\mathrm{kg}$, and the annual meat output of pig, cattle, sheep and poultry was 2.57 million tons. Indeed, its social and economic development is susceptible to natural disasters, especially drought [39]. When drought occurs, the lack of agricultural irrigation water affects crop yield, and the growth of forage is limited, which leads to the shortage of forage for cattle and sheep, and then affects the development of animal husbandry. The degree of impact on agriculture and animal husbandry depends on the severity of drought. Affected by the global warming, droughts occur frequently in the region. Therefore, it is of practical significance to explore the characteristics of drought changes in Inner Mongolia. The entire area is about 1.183 million $\mathrm{km}^{2}$, accounting for $12.1 \%$ of the total area of China. The area is characterised by forests, grasslands, farmlands, deserts, and other ecosystems [36]. Inner Mongolia is located in the south-eastern part of the Mongolian Plateau, with a high altitude. Most of its areas are $>1000 \mathrm{~m}$ above sea level. From the north-east to the south-west, there are staggered plains, mountains, and plateaus. The complex terrain has an impact on the surface distribution of hydrothermal conditions, thus forming a unique natural resource condition in the region [41]. The average annual temperature is $-4 \sim 9{ }^{\circ} \mathrm{C}$ in this region, where summers are short and hot and winters are long and cold. The precipitation is small and uneven with a total annual precipitation of 35 550 $\mathrm{mm}$ and shows a decreasing trend from the north-east to the south-west [42].

\section{Materials and Methods}

\subsection{Data Source}

The monthly temperature and precipitation observation data from 1958 to 2019 are collected from 46 meteorological stations in Inner Mongolia, provided by the China meteorological data sharing service system. The reliable observation data of most stations are from 1958, so we choose this year as the starting time. The pre-processing of data mainly includes: (1) Excluding the sites with more than $1.61 \%$ missing rate of precipitation or temperature data. This missing rate corresponds to 12 missing data of precipitation or temperature. Hence, six sites are excluded from our dataset. (2) Interpolating the stations with fewer missing measurements and using the cubic spline function to interpolate the missing values. The cubic spline interpolation method is selected because of its good smoothness and approximation effect [43]. Finally, 40 stations with a complete sequence are obtained. Figure 1 presents the distribution of the stations in the study area. The total data number of monthly temperature and precipitation data from 40 meteorological stations for this period (i.e., from 1958 to 2019) is 59,520, with 107 missing data, resulting in a missing rate of only $0.18 \%$.

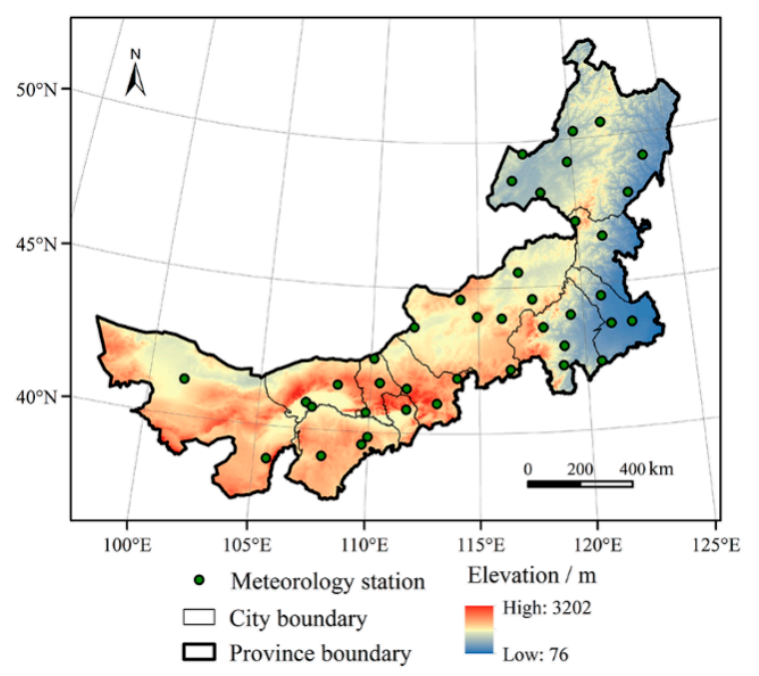

Figure 1. The elevation and distribution of meteorological stations in Inner Mongolia. 


\subsection{SPEI and Its Calculating Methods}

The drought in a region can be characterised using the SPEI, by calculating the degree to which the difference between precipitation and potential evapotranspiration deviates from the average state [44,45]. The SPEI has multiple time scale features. In this study, the SPEI values from 40 sites at different time scales including 1,3, 6, and 12 months are obtained and the SPEI value of the entire study area is also obtained using the Thiessen polygon method. The Thiessen polygon method is a method to calculate the area average precipitation based on the precipitation of discrete precipitation stations. This method has high precision and a simple principle [46], and is suitable for calculating the SPEI value of the entire study area.

The study analyses the monthly droughts, characterised by the SPEI, from January to December on a one month time scale (i.e., SPEI-1), as well as the droughts of spring (March to May), summer (June to August), autumn (September to November), and winter (December to February), characterised by the SPEI on May, August, November, and February on the 3-month time scale (SPEI-3), respectively. Furthermore, the droughts in the plant growth period (March-August), characterised by the SPEI on August on the 6-month time scale (SPEI-6), and the interannual droughts, characterised by the SPEI on December on the 12-month time scale (SPEI-12) are calculated in this study. The Thornthwaite method is a simple way to parameterize PET because of its low requirement for input data: only monthly mean temperature and the latitude of the location are necessary [13]. The data needed by this method is relatively complete and accurate in the study area, so this method is selected to calculate the PET. The calculation process is, as follows [20,47]:

Firstly, we use the Thornthwaite method to calculate the PET.

Then, we calculate the difference between monthly precipitation and evapotranspiration, as follows:

$$
D_{i}=P_{i}-\text { PET }_{\mathrm{i}}
$$

where $D_{i}$ is the difference between precipitation and evapotranspiration, $P_{i}$ is monthly precipitation, and $\mathrm{PET}_{\mathrm{i}}$ is monthly evapotranspiration.

The difference between precipitation and evapotranspiration at different time scales is calculated, as follows:

$$
D_{n}^{k}=\sum_{i=0}^{k-1}\left(P_{n-i}-\operatorname{PET}_{n-i}\right), n \geq k,
$$

where $k$ is the time scale (months) and $n$ is the calculation frequency.

Lastly, the 3-parameter log-logistic probability distribution is used to normalize the cumulative probability density to obtain the SPEI series.

The drought magnitude is classified according to the value of the SPEI and the classification criteria are shown in Table 1 [20].

Table 1. Classifications of drought magnitude based on SPEI value.

\begin{tabular}{ccccc}
\hline No Drought & Mild Drought & Moderate Drought & Severe Drought & Extreme Drought \\
\hline$-0.5<\mathrm{SPEI}$ & $-1<\mathrm{SPEI} \leq-0.5$ & $-1.5<\mathrm{SPEI} \leq-1$ & $-2<\mathrm{SPEI} \leq-1.5$ & $\mathrm{SPEI} \leq-2$ \\
\hline
\end{tabular}

\subsection{ADI and Its Calculating Methods}

In previous studies [37-39], some researchers used the spatial distribution of the occurrence frequency of different types of drought to analyse the spatial distribution of drought intensity in the study area. In this way, it is necessary to prepare a large quantity of maps about the distribution of the occurrence frequency of various degrees of drought, which is not simple and direct, furthermore, none of the maps, solely, would be representative of the drought intensity distribution of the area. Therefore, some scholars used the value of the drought evaluation index to define the drought intensity and evaluate the drought intensity with the spatial distribution of the well-defined drought intensity 
in space. This method is relatively straightforward, however, the drought intensity of a site in space is just a value that integrates the drought conditions of all years and it cannot represent a good picture of the distribution of drought throughout time. Indeed, it cannot show the continuity of drought. However, the drought of the same frequency causes greater damage to the local social and economic development when it occurs continuously.

In order to better reflect the intensity distribution of drought, the ADI based on the SPEI value is proposed, taking into account the effect of continuous drought on the drought intensity in order to evaluate the drought intensity of each site in this study. The calculation formula is as follows:

$$
\mathrm{ADI}=\frac{1}{m} \sum_{i=1}^{m}\left|\mathrm{SPEI}_{i}-\mathrm{t}\right| \times \frac{a}{\bar{a}}, \mathrm{SPEI}-\mathrm{t}<0,
$$

where SPEI- $t$ is the SPEI value at time scale of $t, m$ is the number of years in which SPEI- $t<0, a$ is the number of years of consecutive drought on the site, and $\bar{a}$ is the average number of years of continuous drought for the entire sites in the study area.

To evaluate whether a continuous drought has occurred in a certain year, we define the continuous drought as follows. In the continuous droughts in time series, the droughts in other years are considered as continuous droughts except for the beginning year. For instance, the drought which occurred in 2016, after a drought happened in 2015, will be considered as continuous drought.

It should be noted that the calculation formula of the ADI adopts a concept of relative value, comparing the number of years of continuous drought at each site with the average value of the entire study area, so the result, obtained by the algorithm, is a relative value. In other words, the magnitude of the value has no corresponding drought intensity grading and the magnitude of the value represents the magnitude relationship of the drought intensity at a certain area, in a certain period of time.

\subsection{Mann-Kendall Test}

The Mann-Kendall trend test is a non-parametric statistical test $[47,48]$, with no requirement for the sample to follow a certain distribution and is not disturbed by a few outliers. In this study, the MK test is used to analyse the change trends and mutation-points of drought and the climate conditions of the study area.

The test defines statistics $U F_{k}$ and $U B_{k}$. When the $U F_{k}$ curve exceeds the critical lines, corresponding to different significance levels $(\alpha)$, it indicates that the upward or downward trend is significant at the significance level. If $U F_{k}$ curve and $U B_{k}$ curve intersect between the critical lines, then, the intersection point is the mutation-point.

\section{Results and Discussion}

\subsection{The Changes in SPEI Characteristics over the Years}

The Thiessen polygon method is applied to get the overall SPEI values of the study area. Overall, from 1958 to 2019, Inner Mongolia experienced a wetter period, followed by very frequent droughts. Figure 2a shows the change of the annual SPEI in Inner Mongolia. The SPEI-12 in December can be used to characterise the annual droughts. As it can be seen, the SPEI value shows a clear drop, since 1997. The SPEI values of most years from 1958 to 1996 are positive; only the SPEI value of 1965 is less than -0.5 (referred as mild drought). After 1996, the SPEI values are almost all negative. During the last 23 years (i.e., from 1997 to 2019), only the SPEI values in 1998, 2003, 2012, 2013, and 2018 are positive. As observed from the SPEI cumulative curve, the cumulative value of SPEI shows a general upward trend before 1997, reaching a maximum value of 13.47 in 1996, followed by a downward trend. According to the change of the SPEI values, the frequency of drought began to increase near 1997, experiencing a dramatic change. 


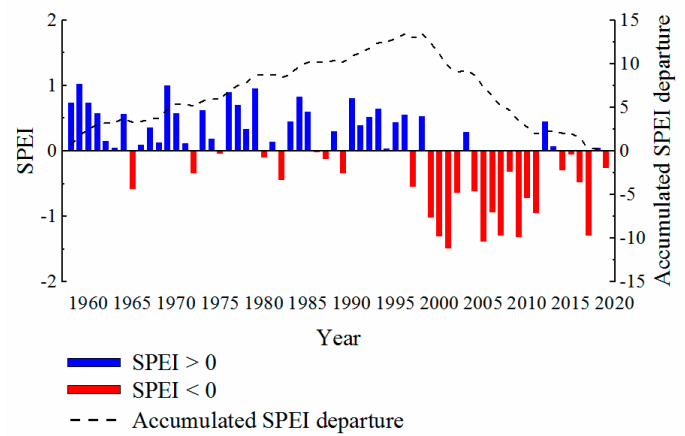

(a)

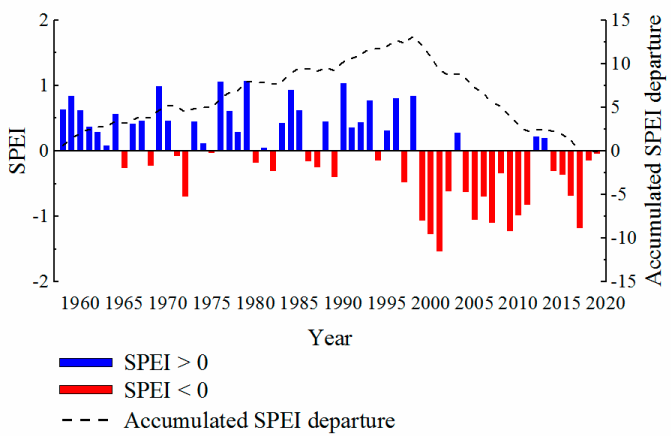

(b)

Figure 2. The (a) changes of annual standardised precipitation evapotranspiration index (SPEI) values and (b) plant growth period SPEI values, over the years.

As previously mentioned, Inner Mongolia is a major province of agriculture and animal husbandry in China and the growth of crops and grasslands affects its agriculture and animal husbandry, respectively. Therefore, in this study, the changes of SPEI values are analysed during plant growth period over the years in the study area. The SPEI-6 in August can be used to characterise droughts during the plant growing season. From the overall trend of the SPEI values during the plant growth period in Figure $2 b$, the drought characteristics of the plant growth period are similar to the annual drought characteristics. Droughts occurred less frequently from 1958 to 1996 and began to occur more frequently since 1997.

To further analyse the drought characteristics in the Inner Mongolia area, the interannual changes of SPEI values in four seasons are analysed (Figure 3). On the whole, the change trends of the SPEI values in spring, summer, and autumn are similar to those of annual and plant growth periods, i.e., mainly humid before 1990s and mainly drought after 1990s. However, the characteristics of trend in winter is contrary to other seasons, showing a phenomenon of drought first, followed by a wet period.

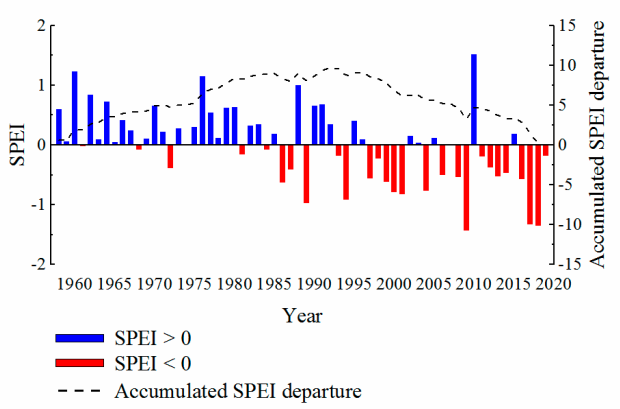

(a)

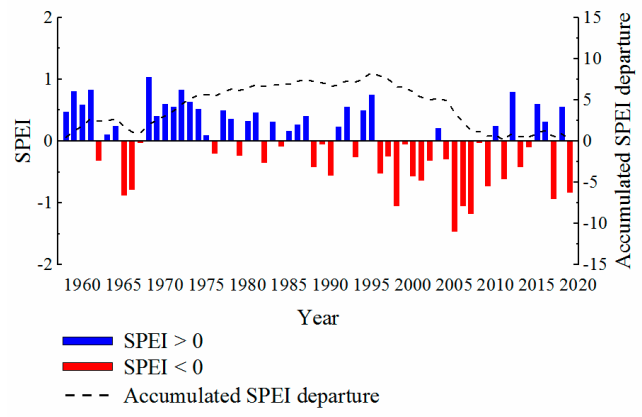

(c)

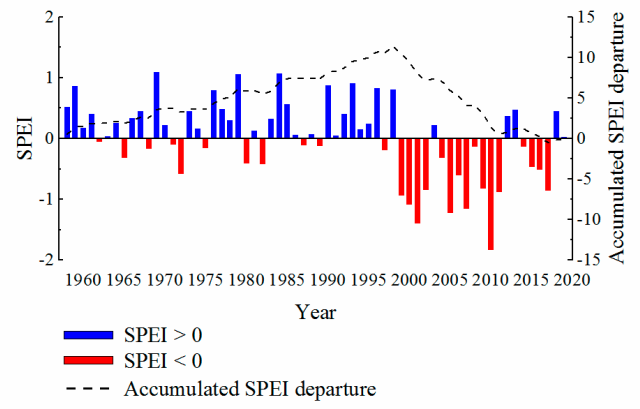

(b)

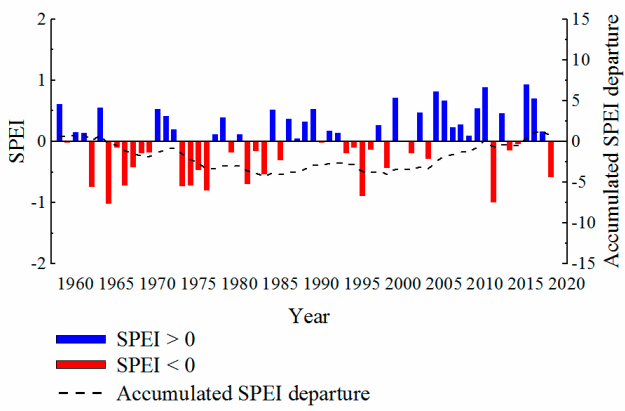

(d)

Figure 3. The changes of SPEI values in (a) spring, (b) summer, (c) autumn, and (d) winter, over the years. 


\subsection{The Spatial Distribution Characteristics of ADI}

The spatial distribution of the drought intensity under different time scales in the entire study area is obtained using the inverse distance weighted interpolation method to interpolate the ADI values at different time scales of each station (Figures 4 and 5).

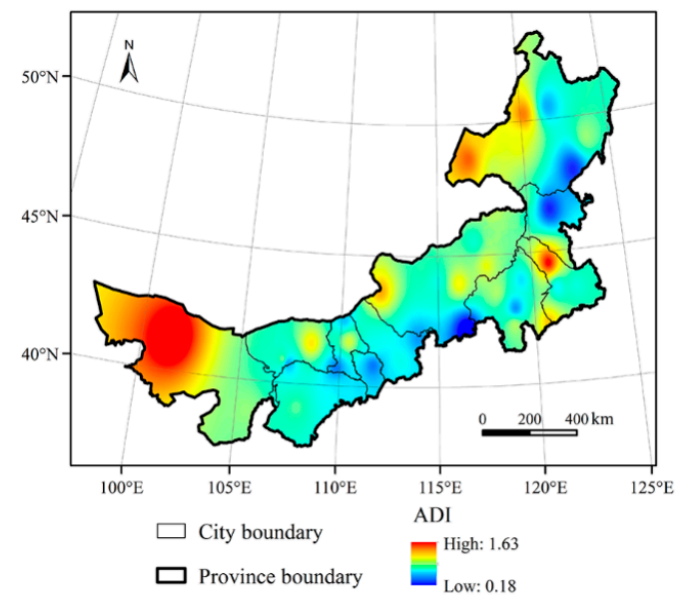

(a)

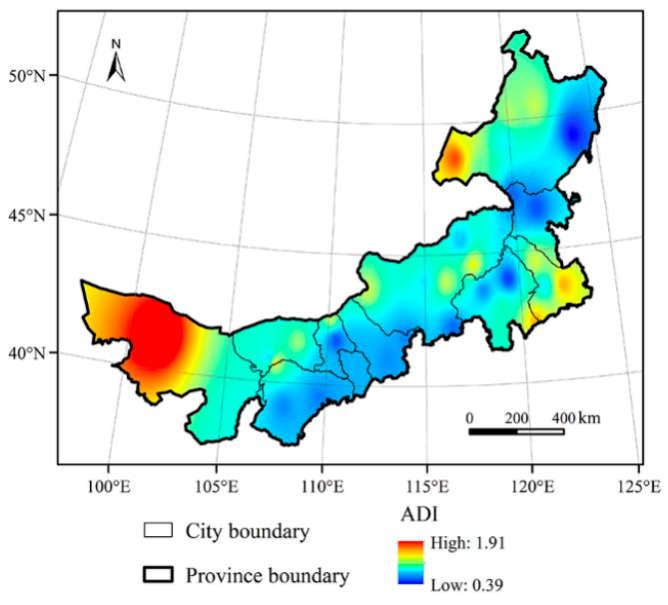

(b)

Figure 4. The spatial distribution of area drought intensity (ADI) values in (a) annual and (b) plant growth period.

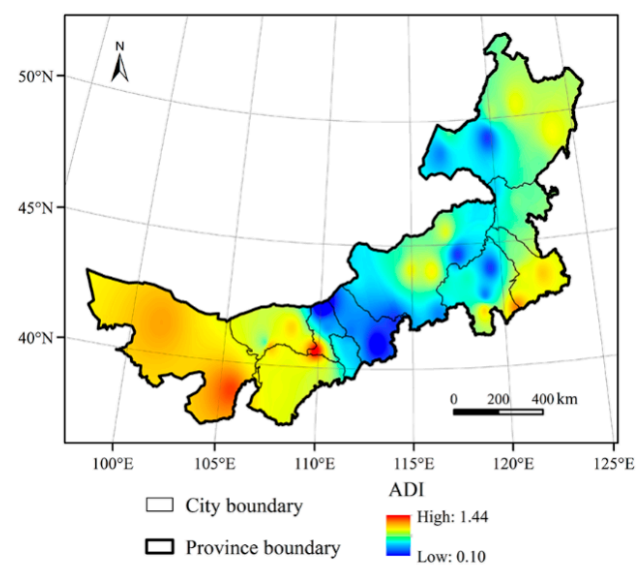

(a)

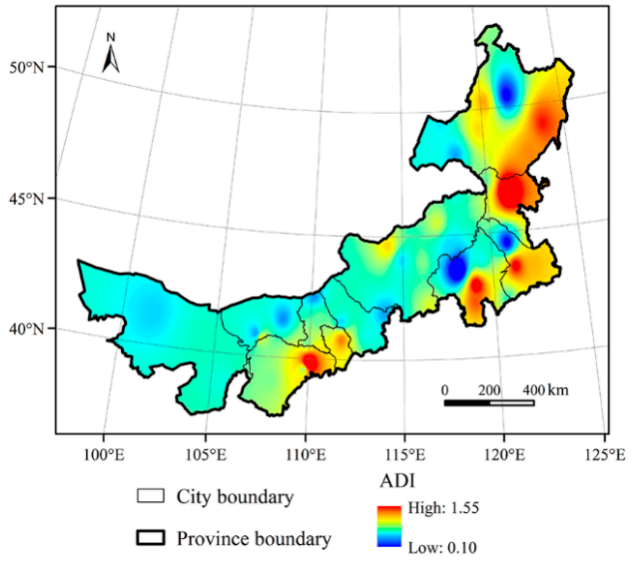

(c)

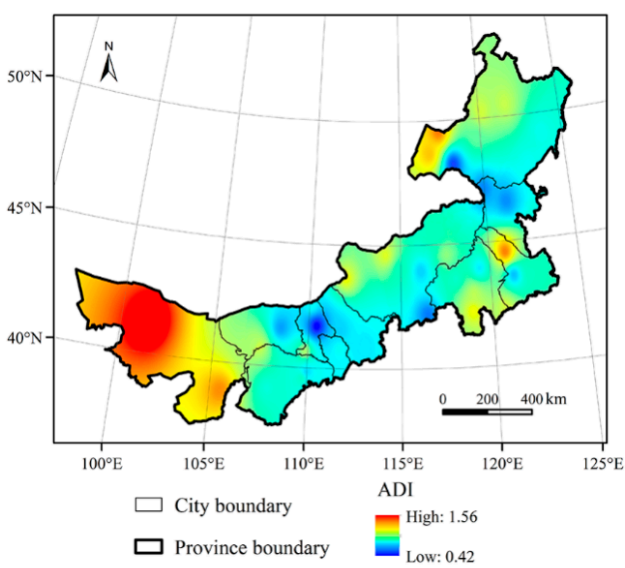

(b)

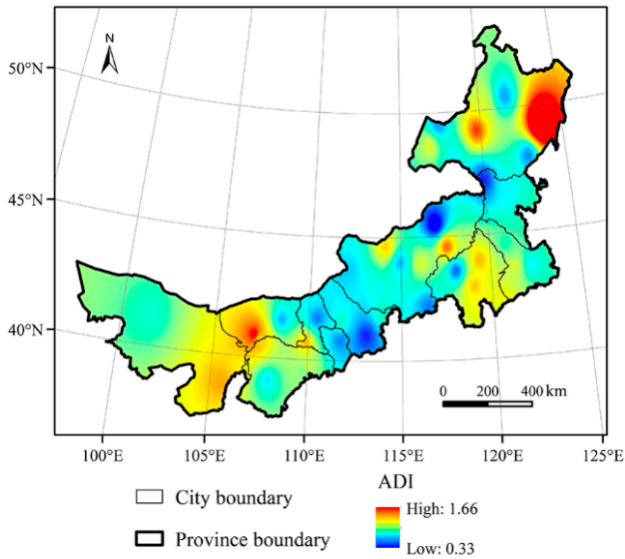

(d)

Figure 5. The spatial distribution of ADI values in (a) spring, (b) summer, (c) autumn, and (d) winter. 
Figure 4 demonstrates the spatial distribution of ADI values in annual and plant growth periods. As present, the spatial distribution of drought intensity between the annual and plant growth periods is basically the same. The drought intensity is high in the western region and low in the central region, in which the north-central has higher values than the south-central. There are different degrees of drought intensity in the eastern region, with a higher value at the north-west and south-east corners.

Figure 5 represents the spatial distribution of the ADI values in four seasons. As observed, spring and summer are characterised by similar spatial drought intensity distribution to the annual and plant growth periods, with a higher intensity at the western area, compared to the central and eastern regions. The drought intensity of the central region is lower than that of the eastern region in spring, while, similar in both regions in summer. The spatial distribution of the drought intensity in autumn and winter differs greatly from the annual and plant growth periods. The drought intensity in autumn is higher in the east of the eastern region and a small part of the central region, while lower in other regions. The drought intensity in winter is higher at the north-east corner, and the distribution of drought intensity in other areas has no obvious regularity with various degrees of drought intensity.

\subsection{The Variation Characteristics of Drought Area over the Years}

Figure 6a represents the changes in the percentage of drought area to the entire study area. According to the change in the five-year moving average of the proportion of drought area, in general the drought area shows rise and fall fluctuation but upward trend, reaching its maximum in 2000s, and tends to decrease after 2010. The drought area has significantly changed since 1997. In 1996, the proportion of drought area is a relatively small value of $8.42 \%$, while, the subsequent 1997 is a mild drought year, in which the drought area has rapidly expanded, reaching up to $62.19 \%$. After that, the drought appears to fluctuate up and down, however, the drought area has significantly increased, compared to years before 1997. Before 1997, there are only few years with drought areas exceeding $50 \%$ and the frequency of large-scale drought events increases significantly after 1997. During these 23 years, 14 years present the drought areas exceeding 50\%, while, for the 8 years, the drought area exceeded $70 \%$. The drought area reaches to its maximum (i.e., $94.28 \%$ ) in 2000.

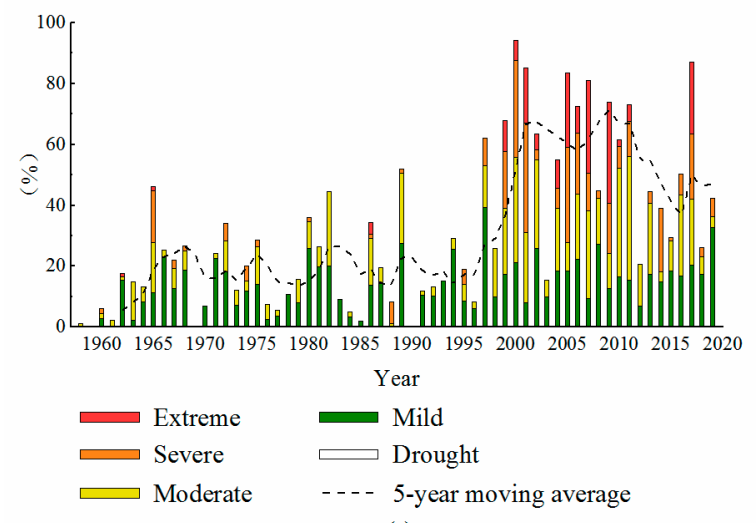

(a)

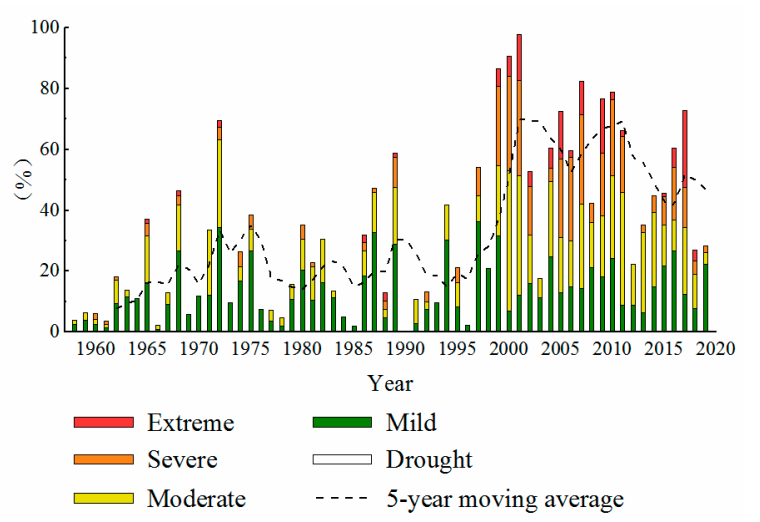

(b)

Figure 6. The changes in the proportion of drought area in (a) annual and (b) plant growth period, over the years.

From the perspective of drought types, from 1958 to 1996, the study area is characterised by mainly mild drought and the frequency of severe drought and extreme drought is extremely small. Between 1997 and 2019, while the drought area is greatly expanded, the type of drought is no longer dominated by the mild drought, moreover, the frequency of moderate drought, severe drought and extreme drought have increased. On the whole, the change characteristics of the drought area are consistent with that of the drought situation, analysed above, both of which take the 1990s as the change point and after the 1990s the drought situation suddenly became severe. Indeed, on the one hand, 
the drought area began to expand rapidly. On the other hand, the degree of drought has intensified, changing from the mild drought to a coexistence of various degrees.

Figures $6 \mathrm{~b}$ and 7 demonstrate the interannual changes in the proportion of the drought area in the plant growth period and all seasons, in which, the changes of the plant growth period and the annual are basically the same. While, the changes of drought area in each season has its own characteristics with an overall increasing trend in the spring, summer, and autumn, with the expansion of the severe and extreme drought areas. The summer, autumn, and winter seasons show the characteristics of regional droughts for consecutive years, with occurrence of regional droughts every year from 1958 to 2019. In spring, the increase in drought area is relatively uniform, with no obvious catastrophic year. The summer drought area suddenly increased in 1999. The drought area during the period between 1999 and 2019 has significantly increased, compared to the previous period, meanwhile, the drought area has declined since 2010. The drought area in the autumn shows an overall increasing trend from 1958 to the 2000s, except the unusually considerable increase in 1962, 1965, and 1966, as well as a downward trend after 2010, which is the same as that in summer. The overall drought area in the winter shows a slight downward trend. However, the drought area in 1995 and 2011 shows unusually great increase, both exceeding $80 \%$. The drought types are mainly dominated by the mild and moderate drought.

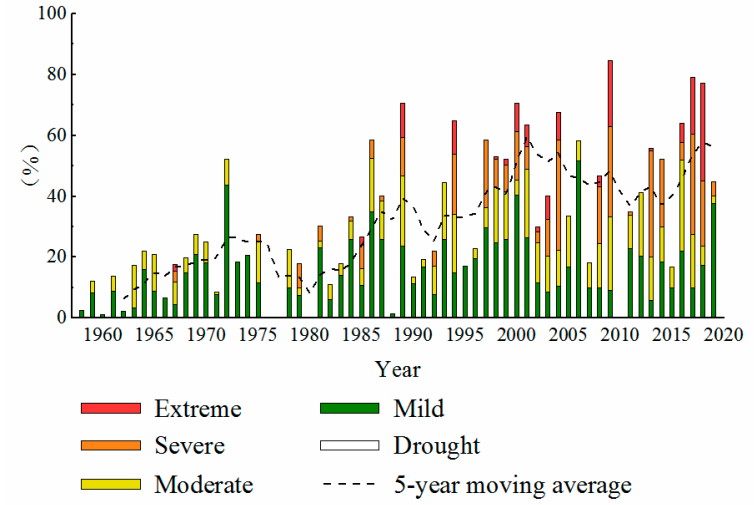

(a)

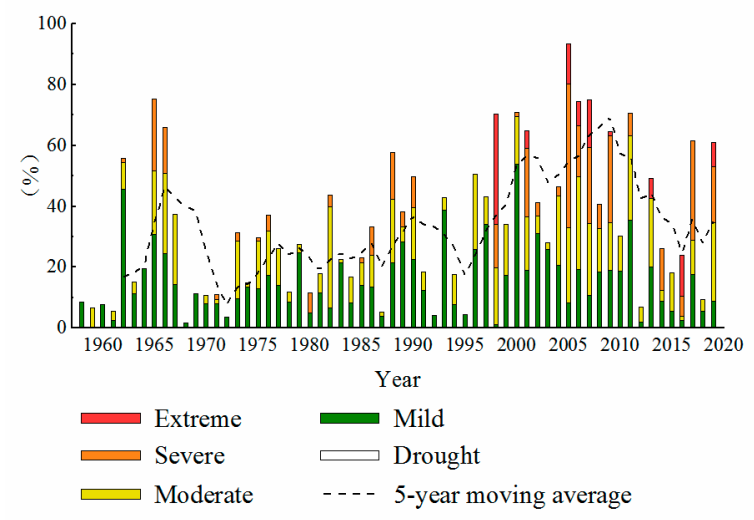

(c)

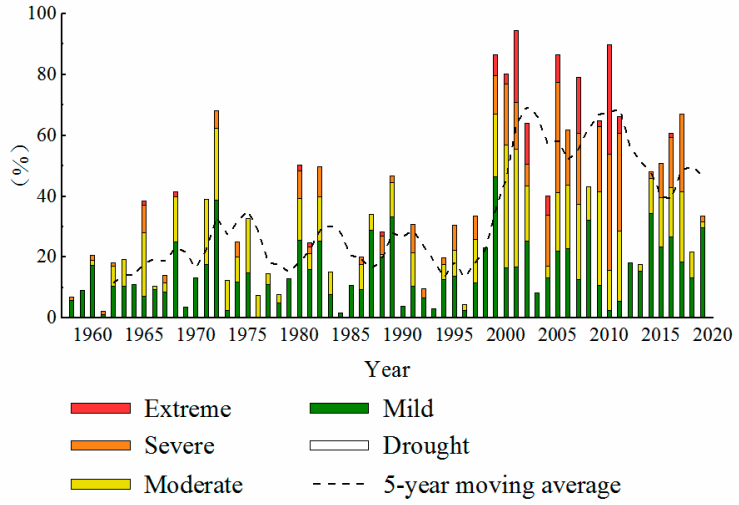

(b)

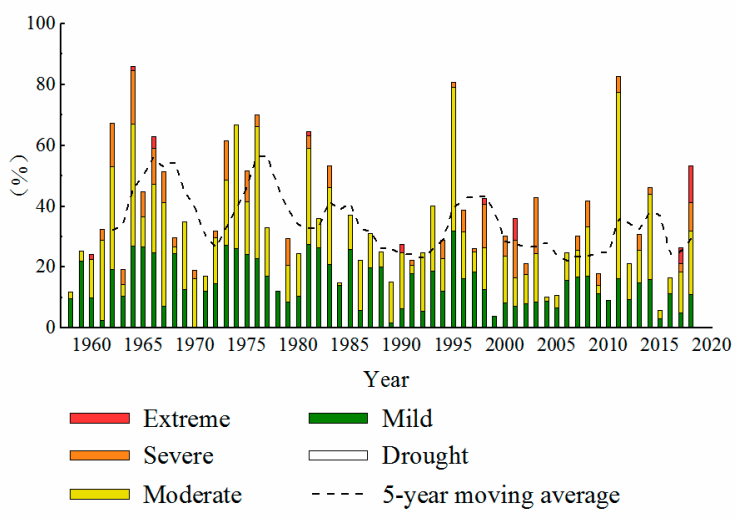

(d)

Figure 7. The changes in the proportion of drought area in (a) spring, (b) summer (c) autumn and (d) winter, over the years.

\subsection{Intra-Annual Variation Characteristics of Drought}

In this study, the intra-annual distribution of drought in Inner Mongolia is analysed using the SPEI values on a 1-month scale (Figure 8). As presented, the frequency of droughts is low before 2000, including mainly the mild droughts. Among the 504 months from 1958 to 1999, only six months show the moderate droughts and one month has a severe drought, with no extreme drought. Since 2000, 
the drought frequency has increased, with more concentration in March-October. The drought types are mainly dominated by the mild drought and the moderate drought, and only one month has experienced severe drought, with no occurrence of the extreme drought. According to the frequency of drought in each month, the frequency of drought in April shows the highest value of $27.4 \%$, while, the drought in January is recorded at its lowest value of $9.7 \%$. According to the drought types, July is the month with the highest frequency of mild drought at $19.4 \%$, April is the month with the highest frequency of moderate drought at $9.7 \%$, while, June and November are the months with the highest frequency of severe drought at $1.6 \%$. The three months of winter (i.e., December-February) are characterised by occurrence of only mild droughts. According to the pattern of drought occurrence in different months, corresponding drought resistance measures should be formulated. For instance, drought-relief workers should be prepared to prevent mild drought impacts in winter, such as applying for a small amount of transferring water.

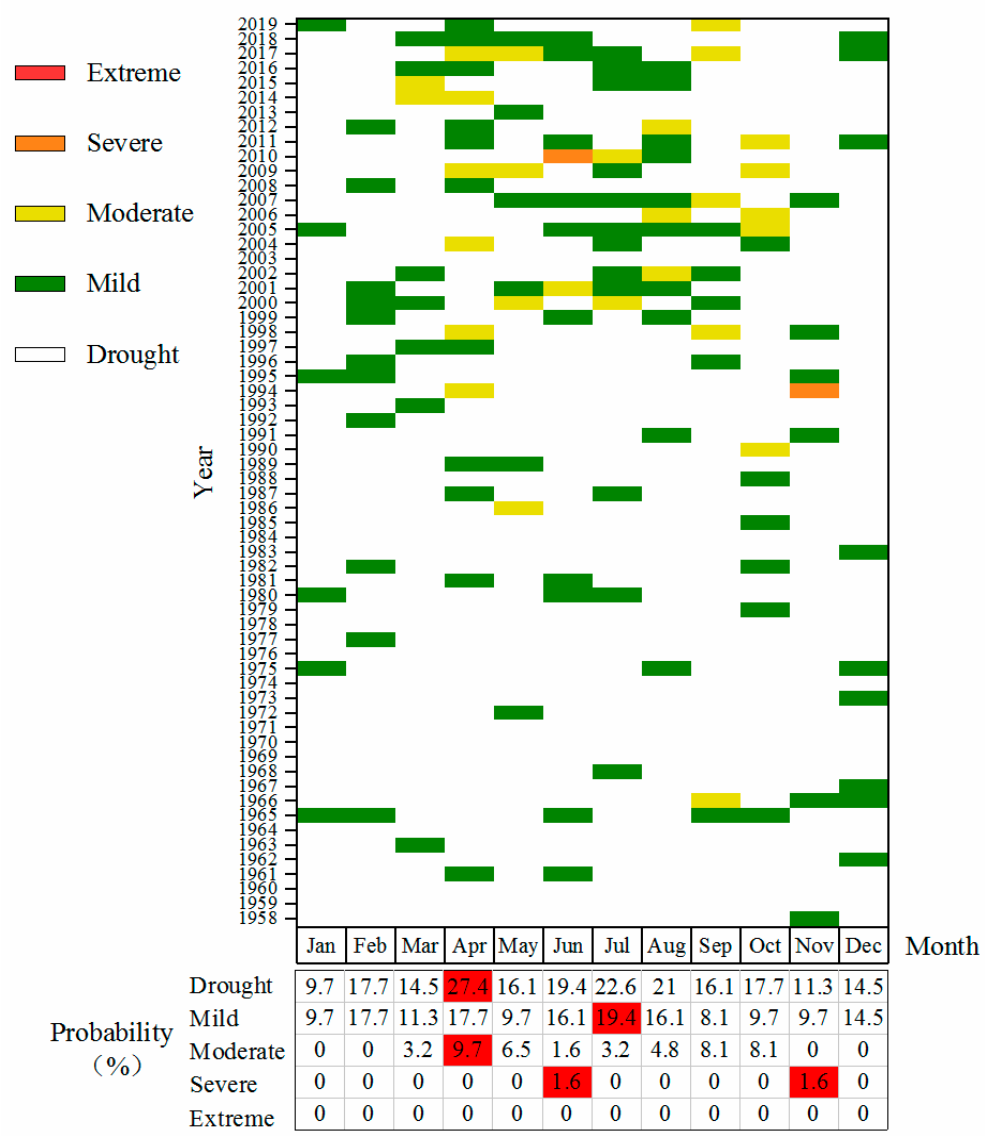

Figure 8. Intra-annual distribution and frequency of droughts.

\subsection{M-K Test}

Based on the previous analysis of the changes in the SPEI values over the years, the SPEI values have significantly changed since the 1990s, hence, the M-K test is used to perform mutation tests on the SPEI values (Figure 9). As observed, the SPEI values begin to have a clear downward trend in 2004 (under the significance level of 0.01). The intersection point of UF and UB is located near 1993, within the critical line of the significance level of 0.01, so the SPEI value mutation has occurred around 1993. 


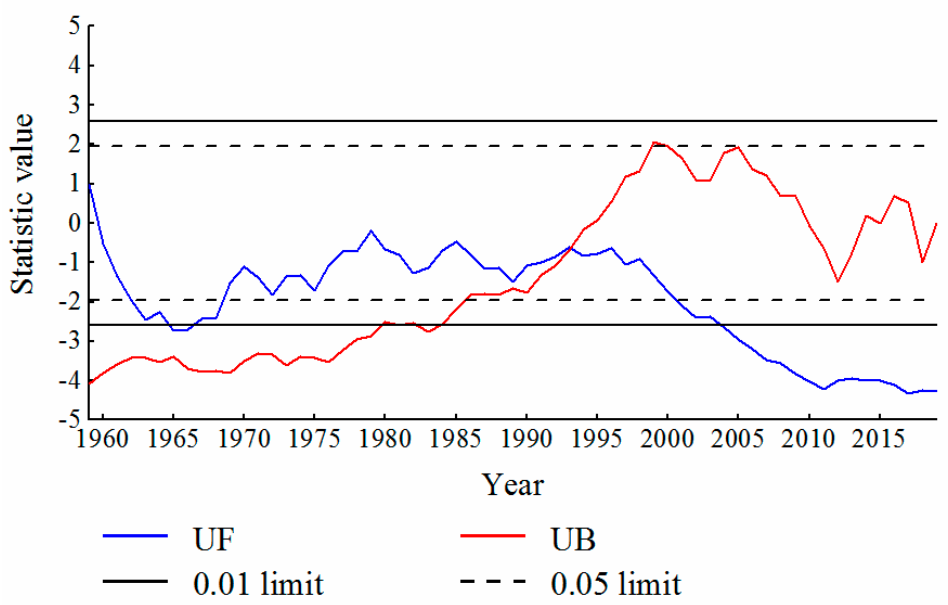

Figure 9. The M-K test result of annual SPEI values.

Precipitation and temperature are considered as the two main factors affecting the SPEI value. SPEI characterizes drought by calculating the degree to which the difference between precipitation and PET deviates from the average state. Therefore, the effect of precipitation and PET on SPEI is obvious. In this study, the Thornthwaite method is selected to calculate the PET, in which only monthly mean temperature and latitude of the location are necessary input data. The latitude of the location will not change, so the change of temperature is the main factor determining the change of the PET and then affecting the SPEI. To further understand the cause of SPEI value mutation, the M-K test is performed on precipitation and temperature. Figure 10 demonstrates the M-K test results of annual average precipitation and annual average temperature of Inner Mongolia. As shown in the figure, no significant change is observed in the precipitation of the Inner Mongolia region, while, the temperature shows a very significant increase in 1993 (under a significance level of 0.01), with the mutation occurrence of near 1991, which is close to the mutation time of the SPEI value. Therefore, it is speculated that the rapid increase in temperature has caused the rapid decline in the SPEI value.

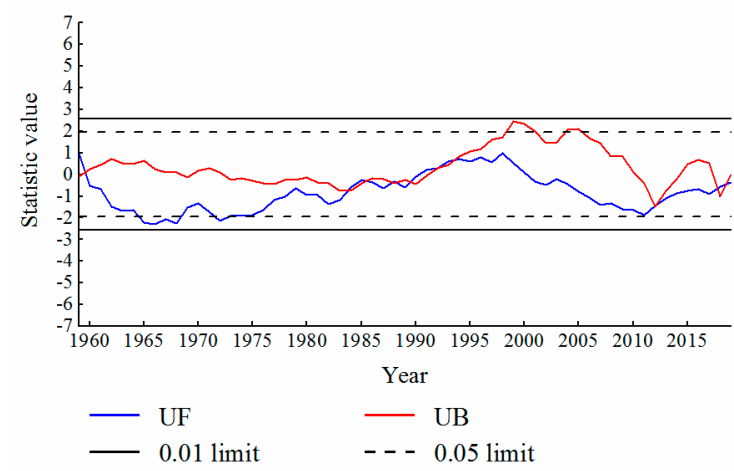

(a)

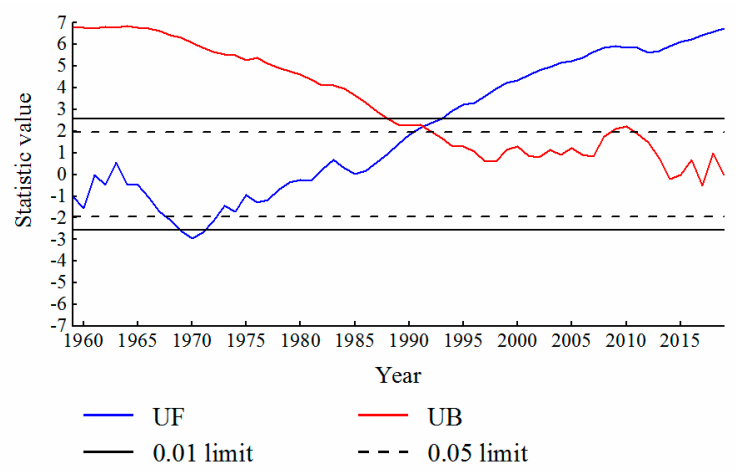

(b)

Figure 10. The M-K test results of (a) annual average precipitation, and (b) annual average temperature.

\subsection{Effects of Climate Warming on Drought Frequency, Duration, and Spatial Distribution}

According to analysis in the Section 4.5, the climate conditions in the Inner Mongolia region show an abrupt change in 1993, leading to aggravation of drought. In order to analyse the change of drought situation before and after the sudden change of climate conditions, the drought occurrence frequency and the longest drought duration are calculated before and after the mutation (Table 2). As shown in the table, the occurrence frequency of drought from 1993 to 2019 is $48.15 \%$, which is 16.85 times that of $2.86 \%$ before the abrupt climate change. The occurrence frequency of mild drought is 7.78 times of that before, with occurrence of only mild drought before the climate mutation. The frequency of 
moderate drought after the mutation is $25.93 \%$, with no severe or extreme drought occurrence before and after the mutation. From the analysis of drought duration, the longest drought duration is seven months before the mutation and 48 months after the mutation, respectively. Furthermore, only the mild drought occurs before the mutation, while, the moderate drought and the severe drought begin to occur after the mutation. After the mutation, the longest durations of the mild drought and the moderate drought are both 13 months, while the longest duration of the severe drought is one month.

Table 2. Comparison of drought frequency and longest drought duration between 1958-1992 and 1993-2019.

\begin{tabular}{cccc}
\hline Item & Degrees & $\mathbf{1 9 5 8 - 1 9 9 2}$ & $\mathbf{1 9 9 3 - 2 0 1 9}$ \\
\hline & Drought & 2.86 & 48.15 \\
Probability (\%) & Mild & 2.86 & 22.22 \\
& Moderate & 0 & $\mathbf{2 5 . 9 3}$ \\
& Severe & 0 & 0 \\
& Extreme & 0 & 0 \\
\hline & Drought & 7 & 48 \\
Longest duration (number of months) & Mild & 7 & 13 \\
& Moderate & 0 & 13 \\
& Severe & 0 & 1 \\
& Extreme & 0 & 0 \\
\hline
\end{tabular}

In order to further analyse the spatial change of drought in Inner Mongolia before and after the abrupt change of climate conditions, the change trend of the SPEI value at each station is calculated in time intervals, and the inverse distance weighted interpolation method is used to obtain the change trend in the entire study area (Figure 11). Due to occurrence of the abrupt climate change in 1993, the time period is divided into 1958-1992 and 1993-2019. It should be noted that the time period is divided according to the change point of sudden climate change and the figure represents the spatial variation of the SPEI in the two periods, not the spatial drought severity. As shown in Figure 11, before the abrupt change of climate, the eastern regions mostly show a humid trend, while most of the western and central regions show a weak drought trend. However, after the abrupt change of climate, the western regions show a very strong drought trend. Meanwhile, a small part of the central regions show a strong drought trend, the southwest of the central region experiences a weaker humid trend, and the other central regions show a weak drought trend. The humid area in the eastern region still occupies a large area, a few areas indicate a strong drought trend, while, the drought trend is weak at the remaining areas.

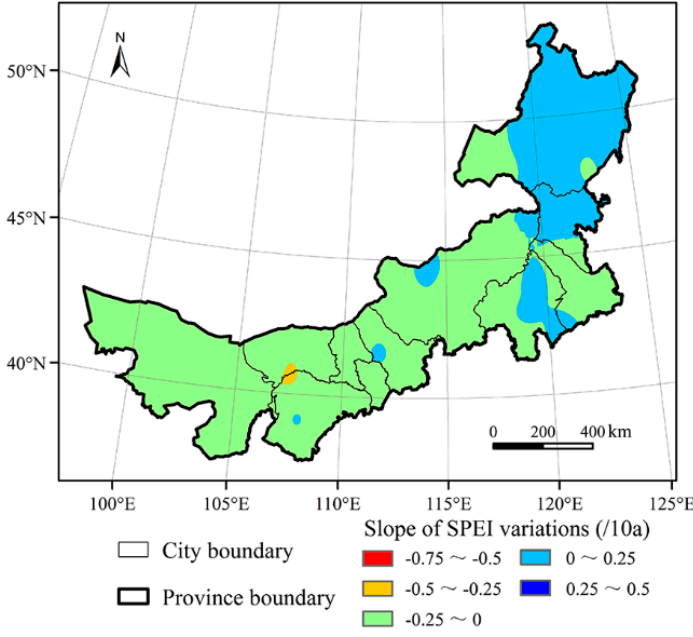

(a)

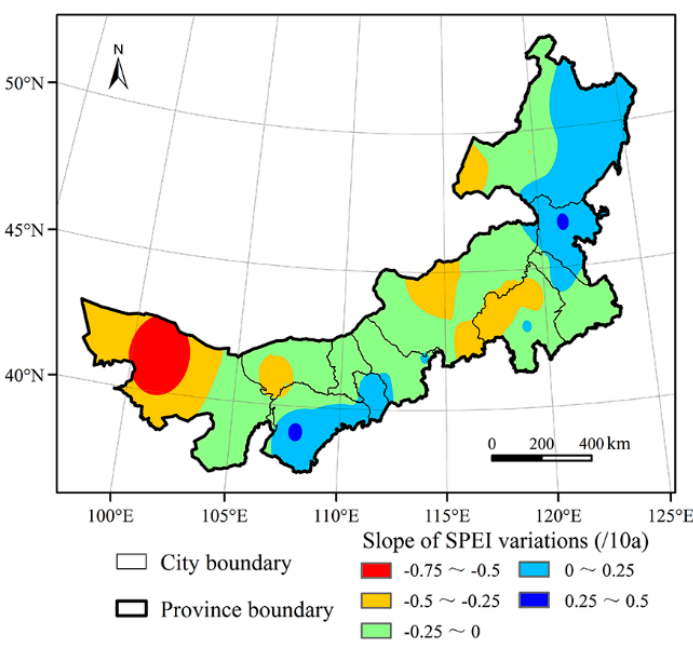

(b)

Figure 11. The annual SPEI spatial changes in (a) 1958-1992 and (b) 1993-2019. 


\subsection{The Spatial Variation Characteristics of Drought Intensity and Frequency}

In order to further analyse the spatial distribution of drought in the study area, the inverse distance weighted interpolation method is used to interpolate the ADI and drought occurrence frequency of each station in order to obtain the distribution of drought intensity and occurrence frequency of the entire study area and to compare the spatial distribution of the ADI and the frequency of droughts at different degrees in 1958-1992 and 1993-2019 (Figures 12 and 13).

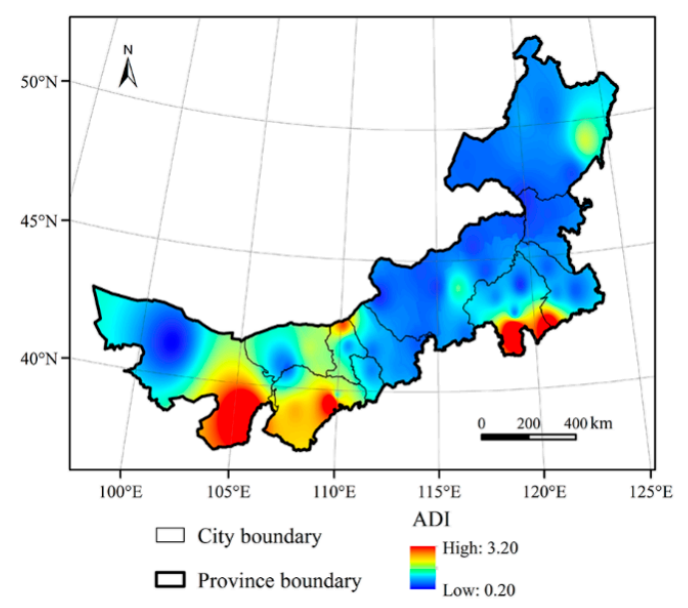

(a)

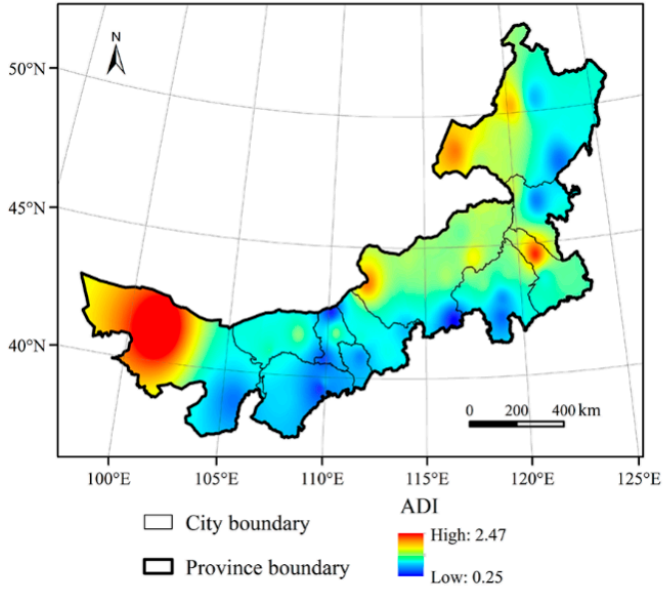

(b)

Figure 12. The spatial distribution of ADI values in (a) 1958-1992 and (b) 1993-2019.

As shown in Figure 12, from 1958 to 1992, the small areas of south-west and south-east show a strong drought intensity (ADI), compared to the weak ADI in the other regions. While from 1993 to 2019 , the drought intensity in the north-west of east, north-west, north-central, and east central regions is strong and in other regions experience a weak ADI. Comparing the two figures, the region with stronger drought intensity has shifted from the south-east to the north-west, after the abrupt climate change.

The spatial distribution of drought occurrence frequency before and after the abrupt change in climate is consistent with that of the drought intensity, and the drought-prone area has shifted from the south-east to the north-west (Figure 13a). The frequency of drought in the south-east before the abrupt climate change is higher, with a maximum of $33.49 \%$. After the abrupt change of climate, the drought frequency in the north-west is higher, with a maximum of $70.68 \%$. Although the drought frequency of the whole region has increased after the abrupt climate change, the drought centrality has indeed shifted after the mutation, compared to the spatial distribution of the drought, before the mutation.

The spatial distribution of different types of drought are analysed in Figure 13b-e. From 1958 to 1992, the frequency of various types of droughts is low, with more concentration in the south-east, which is consistent with the spatial distribution of total drought. Furthermore, the frequency of mild drought is the highest, mainly occurring in the adjacent areas of the west and central regions. The frequencies of the moderate and the severe droughts are lower than that of the mild droughts, mainly covering the south-central regions. The frequency of the extreme drought is the lowest, only occurring in the small areas of the central and north-eastern regions with the highest value of 3.91\%. From 1993 to 2019, the frequency of all types of droughts has significantly increased, showing a clear trend of shifting from the south-east to the north-west in areas with the moderate and severe droughts. The highest frequency of mild drought occurred in the eastern region, with a maximum of $29.32 \%$, while the moderate drought occurred in the north-west corner, with a maximum of 32.41\%. Finally, the severe drought occurred in a small area of the north-central regions and the north-west corner, with a maximum of $18.21 \%$. The distribution of extreme droughts is relatively scattered and the frequency of occurrence is relatively low, reaching a maximum of $8.64 \%$. 

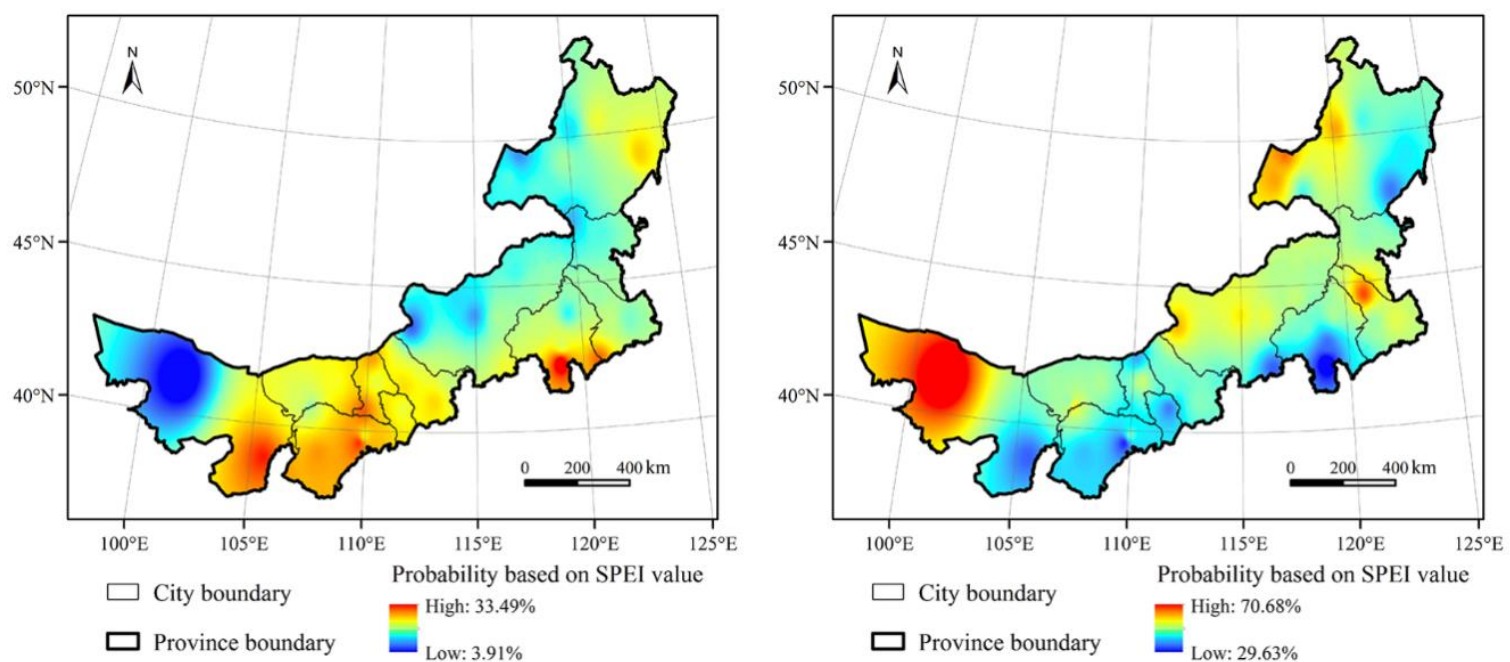

(a)
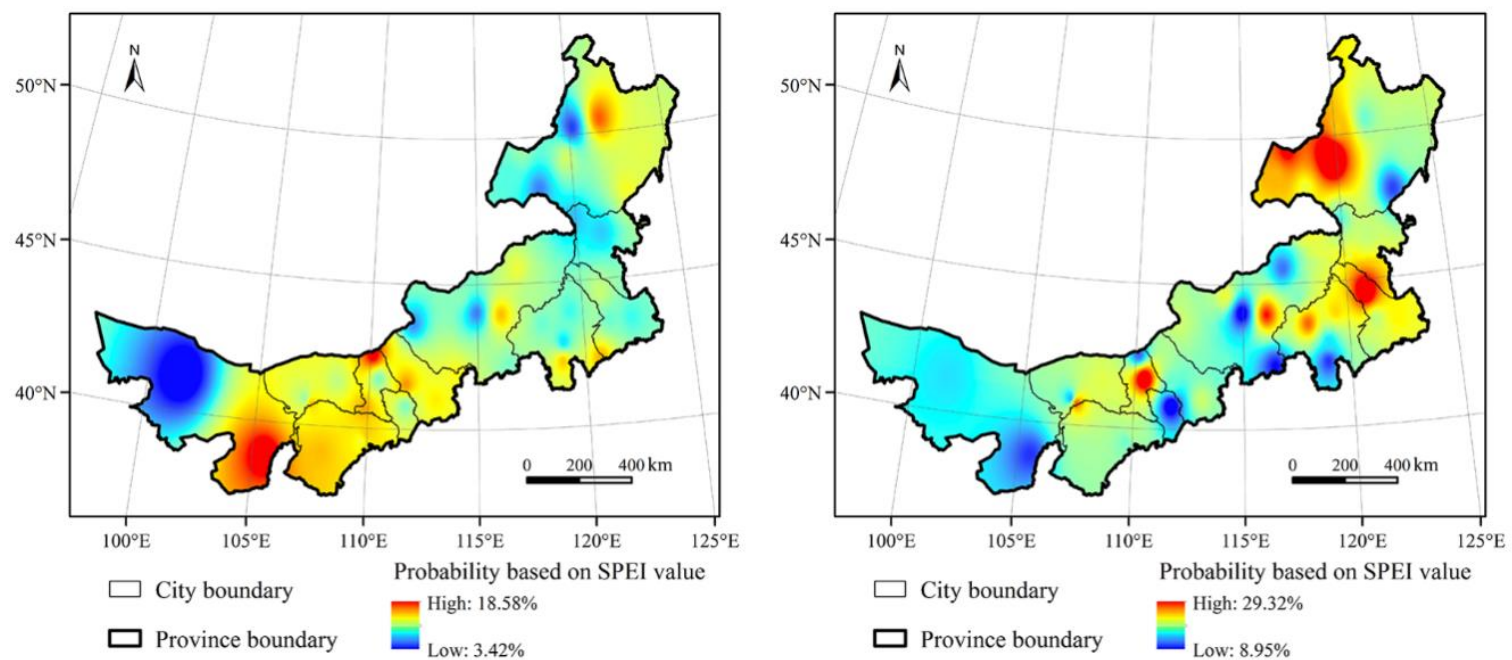

(b)
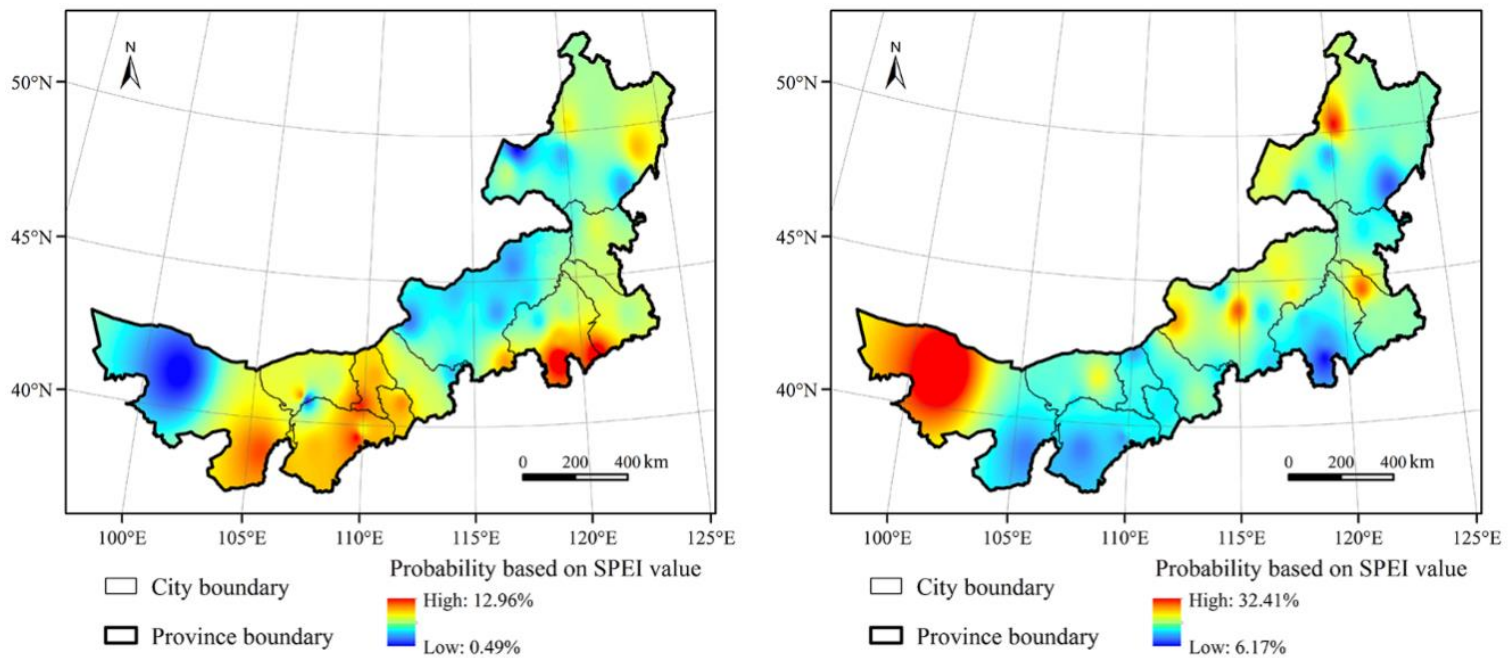

(c)

Figure 13. Cont. 

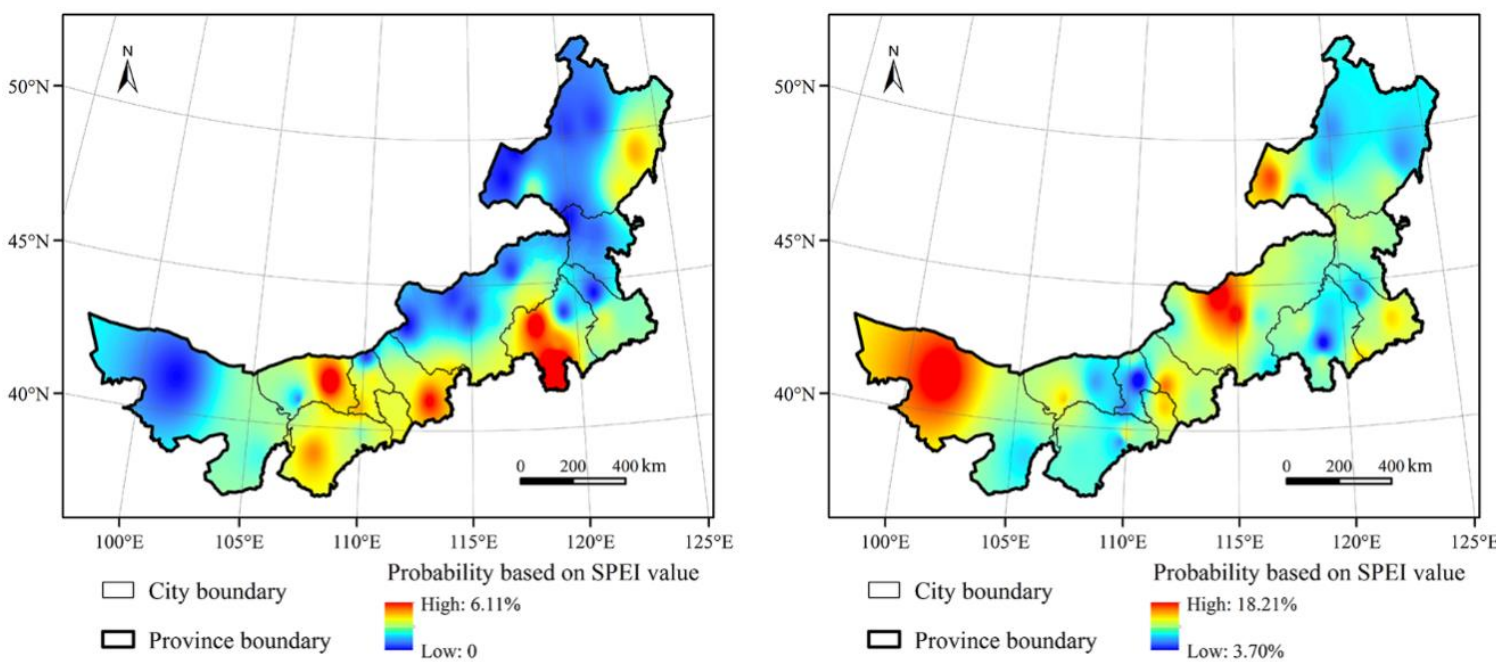

(d)
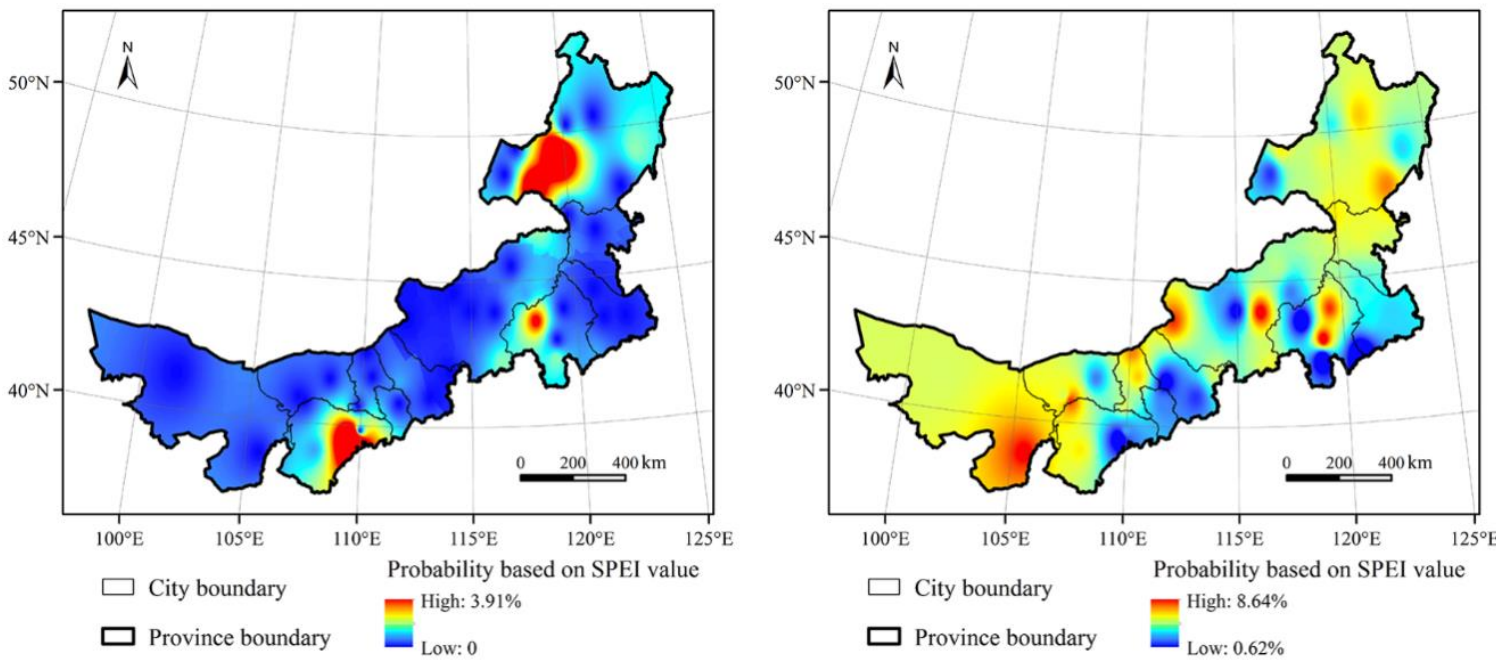

(e)

Figure 13. The spatial distribution of (a) drought, (b) mild drought, (c) moderate drought, (d) severe drought, and (e) extreme drought, in 1958-1992 (left-hand side), and 1993-2019 (right-hand side).

\section{Conclusions}

In this study, the drought situation of Inner Mongolia is studied in detail to analyse the annual change trend, intensity distribution, area range, and intra-year distribution of droughts. Furthermore, the change point of drought mutation and the reasons behind it are explored, and the drought conditions before and after mutation are analysed. It should be noted that the effect of continuous drought is considered in the study of drought intensity. As for the intensity of drought, the future research focus is to find the criteria that can quantify the cumulative effect of continuous drought. The main findings of our study are as follows:

(a) The drought in 1958-2019 shows an overall intensifying trend, with occurrence of a mutation around 1993. Since 1993, the drought situation has rapidly become severe. The changes of droughts in annual, plant growth period, spring, summer, and autumn are all humid at first, followed by a dry situation. However, the trend of drought in winter is opposite to that in other seasons, which is first dry and then humid. 
(b) In general, the drought intensity in the west, north central, and western part of the east regions is relatively strong, while, mostly weak in other regions. The strong drought intensity is located in the western region during spring, in the western and the west-central region in summer, at the eastern border and the small area in the south of the central region during autumn, and in the north-east corner in winter.

(c) The drought coverage area has increased from 1958 to 2019, showing also an increased degree of drought. From 1958 to 1996, the drought is mainly composed of the mild drought, while, from 1997 to 2019, the drought type is no longer dominated by the mild drought, as the frequency of other types of drought has increased. The changes in the drought area in spring, summer, autumn, and plant growth period are consistent with that of the annual drought, showing an increasing trend, while a slight decreasing trend is observed in winter.

(d) The intra-annual distribution of droughts in Inner Mongolia has significantly changed since 2000. Before that, the frequency of droughts was low, mostly dominated by the mild drought. After 2000, drought has begun to occur more frequently, with more concentration in March-October. Moreover, the drought type is dominated by the mild and moderate droughts. April is the month with the highest drought frequency of $27.4 \%$, while, January is the month with the lowest drought frequency of $9.7 \%$.

(e) The climate conditions of Inner Mongolia show an abrupt change in the 1990s, with a clear upward trend of temperature, which can be considered as the reason for the increase of drought in the study area. After the abrupt change of the climate conditions, the frequency and the coverage area of drought, and the duration of continuous drought have significantly increased.

(f) According to the spatial distribution of drought intensity and drought frequency before and after the abrupt climate change, the drought key areas have shifted from the south-east to the north-west, after the abrupt climate change. Among them, this change trend is more obvious in areas with the moderate and severe droughts. Considering the changing trend of the spatial distribution of drought, relevant departments should formulate appropriate response policies, such as developing water-saving agriculture and allocating water resources scientifically, to ensure the normal progress of social and economic development, especially the agricultural and animal husbandry production.

Author Contributions: Data curation, Y.C.; formal analysis, Q.N.; funding acquisition, J.Y.; investigation, J.G.; methodology, Q.A.; software, C.W.; validation, X.X.; writing—original draft, Q.A.; Writing—review and editing, H.H. All authors have read and agreed to the published version of the manuscript.

Funding: The study was financially supported by the National Keypoint Research and Invention Program of the thirteenth (No. 2017YFC0404405), the Youth Program of National Natural Science Foundation of China (No. 51709274) as well as the special funds for scientific research of public welfare in the Ministry of water resources (No. 201501013).

Acknowledgments: We acknowledge to reviewers who helped us in the review process.

Conflicts of Interest: The authors declare no conflict of interest.

\section{References}

1. Cook, B.I.; Mankin, J.S.; Anchukaitis, K.J. Climate Change and Drought: From Past to Future. Curr. Clim. Chang. Rep. 2018, 4, 164-179. [CrossRef]

2. Alamgir, M.; Khan, N.; Shahid, S.; Yaseen, Z.M.; Dewan, A.; Hassan, Q.; Rasheed, B. Evaluating severity-area-frequency (SAF) of seasonal droughts in Bangladesh under climate change scenarios. Stoch. Environ. Res. Risk Assess. 2020, 34, 447-464. [CrossRef]

3. Aadhar, S.; Mishra, V. High-resolution near real-time drought monitoring in South Asia. Sci. Data 2017, 4, 170145. [CrossRef] [PubMed]

4. Beguería, S.; Vicente-Serrano, S.M.; Angulo-Martínez, M. A Multiscalar Global Drought Dataset: The SPEIbase: A New Gridded Product for the Analysis of Drought Variability and Impacts. Bull. Am. Meteorol. Soc. 2010, 91, 1351-1356. [CrossRef] 
5. Dai, A. Drought under global warming: A review. WIREs Clim. Chang. 2011, 2, 45-65. [CrossRef]

6. Ummenhofer, C.C.; D'Arrigo, R.D.; Anchukaitis, K.J.; Buckley, B.M.; Cook, E.R. Links between Indo-Pacific climate variability and drought in the Monsoon Asia Drought Atlas. Clim. Dyn. 2013, 40, 1319-1334. [CrossRef]

7. Fu, C.; Ma, Z. Global change and regional aridification. Chin. J. Atmos. Sci. 2008, 32, 752-760.

8. Cook, B.I.; Smerdon, J.E.; Seager, R.; Coats, S. Global warming and 21st century drying. Clim. Dyn. 2014, 43, 2607-2627. [CrossRef]

9. Seager, R.; Ting, M.; Li, C.; Naik, N.; Cook, B.; Nakamura, J.; Liu, H. Projections of declining surface-water availability for the southwestern United States. Nat. Clim. Chang. 2013, 3, 482-486. [CrossRef]

10. Li, Z.; Chen, Y.; Fang, G.; Li, Y. Multivariate assessment and attribution of droughts in Central Asia. Sci. Rep. 2017, 7, 1-12. [CrossRef]

11. Zhang, L.; Zhou, T. Drought over East Asia: A Review. J. Clim. 2015, 28, 3375-3399. [CrossRef]

12. Ma, Z.; Fu, C. Some evidence of drying trend over northern China from 1951 to 2004. Chin. Sci. Bull. 2006, 51, 2913-2925. [CrossRef]

13. Wang, L.; Chen, W.; Zhou, W. Assessment of Future Drought in Southwest China Based on CMIP5 Multimodel Projections. Adv. Atmos. Sci. 2014, 31, 1035-1050. [CrossRef]

14. Hu, S.; Mo, X.; Lin, Z. Projections of spatial-temporal variation of drought in north China. Arid Land Geogr. 2015, 38, 239-248.

15. Zargar, A.; Sadiq, R.; Naser, B.; Khan, F.I. A review of drought indices. Environ. Rev. 2011, 19, $333-349$. [CrossRef]

16. Palmer, W.C. Meteorological Drought; US Department of Commerce, Weather Bureau: Washington, DC, USA, 1965; Volume 30.

17. Guttman, N.B. Comparing the Palmer drought index and the standardized precipitation index. J. Am. Water Resour. Assoc. 1998, 34, 113-121. [CrossRef]

18. McKee, T.B.; Doesken, N.J.; Kleist, J. The relationship of drought frequency and duration to time scales. In Proceedings of the 8th Conference on Applied Climatology, Boston, MA, USA, 1 January 1993; pp. 179-183.

19. Moreira, E.E.; Paulo, A.A.; Pereira, L.S.; Mexia, J.T. Analysis of SPI drought class transitions using loglinear models. J. Hydrol. 2006, 331, 359. [CrossRef]

20. Vicente-Serrano, S.; Beguería, S.; López-Moreno, J.I. A Multiscalar Drought Index Sensitive to Global Warming: The Standardized Precipitation Evapotranspiration Index. J. Clim. 2010, 23, 1696-1718. [CrossRef]

21. Vicente-Serrano, S.M.; Beguería, S.; López-Moreno, J.I.; Angulo, M.; El Kenawy, A. A New Global 0.5 Gridded Dataset (1901-2006) of a Multiscalar Drought Index: Comparison with Current Drought Index Datasets Based on the Palmer Drought Severity Index. J. Hydrometeorol. 2010, 11, 1033-1043. [CrossRef]

22. Beguería, S.; Vicente-Serrano, S.M.; Reig, F.; Latorre, B. Standardized precipitation evapotranspiration index (SPEI) revisited: Parameter fitting, evapotranspiration models, tools, datasets and drought monitoring. Int. J. Climatol. 2013, 34, 3001-3023. [CrossRef]

23. Hayes, M.; Svoboda, M.; Wilhite, D.; Vanyarkho, O. Monitoring the 1996 Drought Using the Standardized Precipitation Index. Bull. Am. Meteorol. Soc. 1999, 80, 429-438. [CrossRef]

24. Yu, M.; Li, Q.; Hayes, M.J.; Svoboda, M.D.; Heim, R.R. Are droughts becoming more frequent or severe in China based on the Standardized Precipitation Evapotranspiration Index: 1951-2010? Int. J. Climatol. 2014, 34, 545-558. [CrossRef]

25. Hernandez, E.A.; Uddameri, V. Standardized precipitation evaporation index (SPEI)-based drought assessment in semi-arid south Texas. Environ. Earth Sci. 2014, 71, 2491-2501. [CrossRef]

26. Allen, K.J.; Ogden, J.; Buckley, B.M.; Cook, E.R.; Baker, P.J. The potential to reconstruct broadscale climate indices associated with southeast Australian droughts from Athrotaxis species, Tasmania. Clim. Dyn. 2011, 37, 1799-1821. [CrossRef]

27. Potop, V. Evolution of drought severity and its impact on corn in the Republic of Moldova. Theor. Appl. Climatol. 2011, 105, 469-483. [CrossRef]

28. Fuchs, B.; Svoboda, M.; Nothwehr, J.; Poulsen, C.; Sorensen, W.; Guttman, N. A New National Drought Risk Atlas for the US from the National Drought Mitigation Center; National Drought Mitigation Center, University of Nebraska: Lincoln, NE, USA, 2012.

29. Paulo, A.; Rosa, R.; Pereira, L. Climate trends and behaviour of drought indices based on precipitation and evapotranspiration in Portugal. Nat. Hazards Earth Syst. Sci. 2012, 12, 1481-1491. [CrossRef] 
30. Abiodun, B.J.; Salami, A.T.; Matthew, O.J.; Odedokun, S. Potential impacts of afforestation on climate change and extreme events in Nigeria. Clim. Dyn. 2013, 41, 277-293. [CrossRef]

31. Sohn, S.; Ahn, J.; Tam, C. Six month-lead downscaling prediction of winter to spring drought in South Korea based on a multimodel ensemble. Geophys. Res. Lett. 2013, 40, 579-583. [CrossRef]

32. Zhang, R.; Shang, H.; Yu, S.; He, Q.; Yuan, Y.; Bolatov, K.; Mambetov, B.T. Tree-ring-based precipitation reconstruction in southern Kazakhstan, reveals drought variability since A.D. 1770. Int. J. Climatol. 2017, 37, 741-750. [CrossRef]

33. Liang, C.; Shi, T.; Wei, X.; Xu, J.; Hagan, D.; Chen, T.; Dolman, H. Drying and Wetting Trends and Vegetation Covariations in the Drylands of China. Water 2020, 12, 933. [CrossRef]

34. Hu, Q.; Pan, F.; Pan, X.; Zhang, D.; Li, Q.; Pan, Z.; Wei, Y. Spatial analysis of climate change in Inner Mongolia during 1961-2012, China. Appl. Geogr. 2015, 60, 254-260. [CrossRef]

35. Li, Y. The Palmer drought severity index applicability analysis in typical grassland underlying surface area of Inner Mongolia. J. Meteorol. Sci. 2019, 39, 626-634.

36. Qu, X.; Yang, Q.; Wang, H.; Cao, Q.; Lin, C. Characteristics of Meteorological Drought Intensity in Inner Mongolia Based on MCI. Meteorol. Environ. Sci. 2019, 42, 47-54.

37. Wu, Y.; Li, W.; Wang, W.; Quan, Q.; Chen, X.; Yi, H.; Zhou, Q.; Xu, K. Drought Characteristics in Inner Mongolia Based on Precipitation Anomaly Percentage. Arid Zone Res. 2019, 36, 943-952.

38. Zhou, Y.; Li, N.; Ji, Z.; Gu, X.; Fan, B. Temporal and Spatial Patterns of Droughts Based on Standard Precipitation Index (SPI) in Inner Mongolia during 1981-2010. J. Nat. Resour. 2013, 028, 1694-1706.

39. Zhang, X.; Pan, X.; Xu, L.; Wei, P.; Yin, Z.; Shao, C. Analysis of spatio-temporal distribution of drought characteristics based on SPEI in Inner Mongolia during 1960-2015. Trans. Chin. Soc. Agric. Eng. 2017, 33, 190-199.

40. Yao, J.; Zhao, Y.; Chen, Y.; Yu, X.; Zhang, R. Multi-scale assessments of droughts: A case study in Xinjiang, China. Sci. Total Environ. 2018, 630, 444-452. [CrossRef] [PubMed]

41. Wang, X.; Pan, X.; Gu, S.; Hu, Q.; Wei, P.; Pan, Y. Trend in reference crop evapotranspiration and meteorological factors affecting trends in Inner Mongolia. Trans. Chin. Soc. Agric. Eng. 2015, 31, 142-152. [CrossRef]

42. Ya, R.; Li, N.; Yin, S.; Bao, Y. Characteristics of Temporal and Spatial Variation of Extreme Climate Events in Inner Mongolia During the Period 1960-2015. Res. Soil Water Conserv. 2020, 27, 106-112.

43. Wang, J.; Li, Y.; Yang, G.; Zhang, N.; Cao, Y. Cubic Spline Interpolation-Based Method for Line-Like Phase Errors of Phase Unwrapping. Opt. Optoelectron. Technol. 2019, 17, 23-29.

44. Li, J.; Yue, Y.; Pan, H.; Ye, X. Variation rules of meteorological drought in China during 1961-2010 based on SPEI and intensity analysis. J. Catastrophol. 2014, 29, 176-182. [CrossRef]

45. Ming, B.; Guo, Y.-q.; Tao, H.-b.; Liu, G.-z.; Li, S.-k.; Wang, P. SPEIPM-based research on drought impact on maize yield in North China Plain. J. Integr. Agric. 2015, 14, 660-669. [CrossRef]

46. Yan, Z.; Mu, G. Surface Precipitation Calculation of River Basin Based on Thiessen Polygons Method. Water Conserv. Sci. Technol. Econ. 2017, 23, 19-22.

47. An, Q.; He, H.; Gao, J.; Nie, Q.; Cui, Y.; Wei, C.; Xie, X. Analysis of Temporal-Spatial Variation Characteristics of Drought: A Case Study from Xinjiang, China. Water 2020, 12, 741. [CrossRef]

48. Gocic, M.; Trajkovic, S. Analysis of changes in meteorological variables using Mann-Kendall and Sen's slope estimator statistical tests in Serbia. Glob. Planet. Chang. 2013, 100, 172-182. [CrossRef]

(C) 2020 by the authors. Licensee MDPI, Basel, Switzerland. This article is an open access article distributed under the terms and conditions of the Creative Commons Attribution (CC BY) license (http://creativecommons.org/licenses/by/4.0/). 